\title{
Adapting and Implementing Appreciative Advising Framework to Train Orientation Leaders
}

\author{
Amanda E. Propst Cuevas, Claire Robinson, Amanda Clark, Bryant L. Hutson, \\ and Jennifer L. Bloom
}

Expanding upon the work of Hendley (2010) who introduced the concept of adapting the six phase Appreciative Advising framework (Bloom, Hutson, \& He, 2008) to orientation leader training, this article demonstrates how to construct and implement an effective training program for orientation leaders. It provides practical application of each phase of Appreciative Advising for both orientation training facilitators and orientation leaders. In doing so, this article demonstrates how the six phases of Appreciative Advising offer a framework that incorporates and emphasizes the development of the informational, conceptual, and relational skill sets desired from orientation leaders. This development begins during training and transcends to leaders' interaction with incoming students. Appreciative approach to training has the power to positively impact the orientation leaders as well as new students.

One of the main purposes of orientation programs in higher education institutions is to convey information to first-year and transfer students to enable successful transition into their new collegiate environments. Therefore, training of orientation leaders focuses on teaching information that they will need to convey to new students and their family members. Orientation leaders also need to know the best way to effectively convey information to new students (relational skills) and understand the "why" behind the content they share and its relevance to their own academic careers (conceptual skills). Otherwise, the information relayed by orientation leaders may less likely be understood and absorbed by incoming

Amanda E. Propst Cuevas (cuevasam@gvsu.edu) is the Director of the Office of Fellowships housed in the Frederik Meijer Honors College at Grand Valley State University.

Claire Robinson (Claire.Robinson@sc.edu) is the Associate Director of the Student Success Center and Director of the Academic Centers for Excellence at the University of South Carolina.

Amanda Clark (clarkaj7@mailbox.sc.edu) is a first-year graduate student in the Higher Education and Student Affairs Program at the University of South Carolina.

Bryant Hutson (blhutson@uncg.edu) is Associate Director for Student Academic Services at the University of North Carolina at Greensboro.

Jennifer L. Bloom (bloomjl@mailbox.sc.edu) is a Clinical Professor and Director of the Higher Education and Student Affairs Master's Degree Program at the University of South Carolina. 
students and their families.

Habley $(1986,1995)$ described the three components of effectively training academic advisors: conceptual, informational, and relational elements. He noted, "Without understanding (conceptual elements), there is no context for the delivery of services. Without information, there is no substance to advising. And, without personal skills (relational), the quality of the advisee/advisor relationship is left to chance" (p. 76). This "three-legged stool" of training advisors is transferrable to training orientation leaders. One leg of the stool cannot be neglected without risking the effectiveness of training.

Hendley (2010) first introduced the concept of adapting the six phase Appreciative Advising framework (Bloom, Hutson, \& He, 2008) to orientation leader training. Appreciative Advising has also been adapted for use in a number of student affairs areas, including career counseling, tutoring, and financial aid (Bailey-Taylor, 2009; Grogan, 2010; Traynor \& Bloom, 2009). Additionally, Fippinger (2009) utilized the Appreciative Advising model to train undergraduate student admissions workers. This article expands on Hendley's (2010) work in order to present a framework which focuses on the conceptual and relational aspects of training while leaving room within the framework for inserting institution-specific informational components of training.

\section{Appreciative Advising Overview}

According to Bloom et al. (2008), the six phases of Appreciative Advising are: Disarm, Discover, Dream, Design, Deliver, and Don't Settle. Appreciative Advising is focused on creating a trusting relationship with students (Disarm) by bringing out the best in students through the use of positive questions that elicit stories from students about their past accomplishments (Discover) and their personal and professional dreams for their futures (Dream). After this information has been acquired, the advisor and students work together to create a plan for accomplishing their dreams (Design) before sending students out to execute that plan (Deliver). The last phase, Don't Settle, is where the advisor encourages students to continue to always strive to be lifelong learners and seek to continuously improve their performance.

\section{Benefits of Appreciative Advising Framework}

There are many benefits to adapting the six phases of Appreciative Advising to training orientation leaders. Fippinger (2009) noted that the benefits accrue to student leaders, the new students they serve, and to the offices and institutions that employ them. Orientation leaders benefit because they will be positioned to help new students adjust to college life, and they will learn important relational skills allowing them to be more effective communicators with their families and friends (Howell, 2010). In addition, orientation leaders will have an opportunity to reflect on their own educational journeys and on how the lessons learned will serve them well as they eventually transition into the next phase of their own lives. Lastly, by 
going through the six phases of Appreciative Advising during training, they will learn a valuable framework useful in other areas of their lives, including career planning (Martin \& Bloom, 2002).

The new students will benefit from interacting with and learning from welltrained, soon-to-be peers. The institutions will benefit because both the orientation leaders and new students will have had positive, growth-inducing experiences through their participation in the orientation process, enhancing the sense of community on campus.

Orientation leaders, already a part of the campus community, are often the first peers whom incoming students will meet. Therefore, orientation leaders offer the first impression of what other students on campus might be like. They will be the first peers to assist incoming students with negotiating the institutional culture and expectations and provide insights into how faculty and staff interact with students. The approach that orientation leaders take in assuming these roles will significantly influence the extent to which incoming students feel that they can successfully become a part of the campus community. Orientation leaders who are trained in Appreciative Advising, and who have themselves benefited from this approach through training, can help substantially improve incoming students' commitment to the institution and strengthen incoming students' conviction to successfully complete their course of study. First impressions of the institution provided by orientation leaders can have a great impact on enrollment, retention, and graduation rates.

\section{Applying the Appreciative Advising Framework}

During training, as orientation leaders are taught information that they should provide to students and their families, relational skills can be introduced to teach orientation leaders how to facilitate ice-breakers and small group discussions. To effectively train orientation leaders to help incoming students transition into the institution, it is important to reflect on what specifically orientation leaders are to learn, how they should apply what they learn, and what the long-term impact ought to be. The following sections of this article will describe each phase of Appreciative Advising and provide sample activities and questions that can be utilized during training.

\section{Disarm}

Orientation leaders have a remarkable opportunity to make a lasting first impression on students during their first official visit to campus as admitted students. Not only can orientation leaders provide new students with pertinent information, they can also serve as role models. To assist orientation leaders in setting a positive tone for new students, their training should focus on how to effectively disarm and welcome students during this crucial time.

The Disarm phase is defined as recognizing the importance of first impressions 
while creating a safe, welcoming environment for students (Bloom et al., 2008). Orientation leaders should prioritize this welcoming behavior in their interactions with students. The social-psychology literature reveals that people make a judgment on whether or not someone will be helpful within seconds of their first meeting (Boothman, 2008). If an orientation leader sets a negative first impression, new students are likely to start their college experience feeling defensive, uncomfortable, and even fearful that they may have made the wrong decision. Conversely, if the orientation leader disarms and welcomes students enthusiastically, new students are likely to transition more easily, feeling excited and confident in their decision.

\section{Director/facilitator toolbox}

There are several ways to train orientation leaders on how to effectively disarm. First and foremost, the simple act of smiling and shaking hands quickly sets the tone that we (the campus) are happy that new students and their families have arrived at the college or university. The orientation leader should enthusiastically welcome students and their families by saying something like, "Hello! My name is __. Welcome to [institution]. We are excited you are here! Orientation is an exciting time. Please let me know if I can help with anything or answer any questions."

The importance of the Disarming phase should be emphasized to orientation leaders during training. They should practice the disarming techniques. It is especially important for orientation leaders who might be slightly quiet or reserved to rehearse greeting people as they first meet them.

\section{Disarm activities}

- $\quad$ Guided Imagery

- Everyone, close your eyes. Think back to when you came to orientation here at this campus. What emotions did you experience as you drove onto the campus? What did you expect out of your orientation experience? What did you take away from your orientation experience? What about your orientation experience led you to apply to be an orientation leader?

- Campus Memory Map

- Share with us your personal stories related to finding places on campus. (The trainers can summarize the campus map while going over orientation leaders' personal stories to help them get to know each other.)

- Meet and Greet

- Participants, please begin milling about the room. Greet each other, perhaps just by shaking hands. Then move on and greet the next participant you meet. Try to greet each other in more specific ways, such as:

- Greet each other like you would greet a long lost friend.

- Greet someone you don't really trust.

- Greet someone who sold you a crappy used car 
- Greet someone like you are a cowboy, a soldier, a nanny, a Russian farmer... (Retrieved from: http://improvencyclopedia.org/games/ Greetings.html).

\section{Orientation leader toolbox - disarm questions}

Another practical way to train orientation leaders to effectively disarm new students is to provide them with sample questions to ask new students during orientation:

- What have been your first impressions of the campus?

- Introduce yourself to your neighbors as if they are your long-lost best friends, asking them, "What has been the highlight of your summer so far?"

- If you had to describe what you are feeling right now in three words, what words would you choose?

Regardless of how training is organized, a significant portion of time should be spent on the Disarm phase as it serves as a gateway to the remaining phases. Directors or facilitators of training should consider how to intentionally welcome the orientation leaders when they first arrive. Many students may have had a negative experience with a staff member and are often apprehensive of "authority" figures on campus (Bloom et al., 2008). Orientation provides a tremendous opportunity to positively impact a large number of students, parents, and families.

\section{Discover}

The Discover phase provides orientation leaders with an approach to learn more about the new students they will meet during orientation. This phase utilizes positive, open-ended questions to draw out students' interests, strengths, and passions (Bloom et al., 2008). A key component of the Discover phase is encouraging orientation leaders to listen to students' answers carefully before asking the next positive question.

\section{Director/facilitator toolbox}

Facilitators can use a variety of activities to practice this phase during training.

- $\quad$ Lifeline exercise

- Have orientation leaders reflect on their own personal story, including significant life events, what is meaningful to them, and what brought them to this campus.

- Five-minute pairing exercise

- Pair orientation leaders and give them five minutes to find out as much as they can about their partner in terms of their relationship to the university. They may also ask each other questions, such as:

- Tell me about a time when you helped someone deal with a situation they were afraid to face? 
- What emotions did you feel when you first arrived on campus?

- Who was instrumental in helping you adjust to campus life?

Debrief with discussing the strategies they used to engage their partner in conversation.

\section{Orientation leader toolbox - discover questions}

The following Discover questions can be used during orientation training to draw out the individual stories of the orientation leaders:

- Tell me about a time that you successfully dealt with a challenging situation?

- When did you first know that you would go to college? When and why did you decide to attend this institution?

- What inspired you to become an orientation leader?

- What experiences did you have during orientation that you would like new students to experience?

These questions require students to answer by telling a story (Bloom et al., 2008). Good questions enable students to reflect on their experiences and share aspects about themselves that they enjoy, feel proud of, and want others to know. Furthermore, effective questions and answers serve as the foundation for the rapport between the orientation leader and new students, promoting the "relational" component of the orientation leader role.

\section{Dream}

First-year students dream of making new friends, getting good grades, having a social life, taking on leadership roles, and enjoying the new experiences in their lives. In the Disarm phase, orientation leaders make students feel welcome to campus. In the Dream phase, orientation leaders provide the student with an opportunity to identify some aspirations or goals they may have for their first year in college. The Dream phase can position orientation leaders to later see the connections between their opportunities during college and how those opportunities can help students fulfill their hopes and dreams for their future.

\section{Director/facilitator toolbox}

- Guided imagery

- $\quad$ Close your eyes and picture your ideal future. Describe what you see. Where are you living? What are you doing? Who are you with? Envision how your experiences as an orientation leader this summer will help you reach that ideal future.

- William "Shoes" Johnson (personal communication, 2007) Dream Exercise

- Give students/orientation leaders one minute to write down all the goals they have for themselves in college. Pair students and have them share 
one or two of their goals. Then, brainstorm ways they could reach them. The orientation leader can be trained to provide resources, tips, and strategies.

- University image

- Draw/create an image of your ideal university. What is the culture of the campus? Who are your professors? Who are your friends? What will be your fondest memories of this institution when you graduate?

Below are sample questions which directors/facilitators could ask during training to encourage orientation leaders to share their dreams and goals.

- If you could design the ultimate orientation for incoming students, what would that look like?

- If you won $\$ 20$ million today with the condition that you had to work 40 hours per week doing whatever you wanted, what job would you select? Why?

- What would you want incoming students to remember about you one year later?

\section{Orientation leader toolbox - dream questions}

- What are three goals you have for your first semester in college?

- If you could have any leadership role on campus, what would it be and why?

- Envision your ideal first semester. What would it include? What would you like to achieve academically? Socially? Through involvement?

Finally, an important component of the Dream phase is to remind both orientation leaders and students that there is more than one right answer (Bloom et al., 2008). There are many ways to achieve a dream, and college will provide a multitude of those opportunities.

\section{Design}

The Design phase offers a tangible plan of action to assist students in turning their dream into reality. Dictionary.com defines "design" as follows: "To prepare the preliminary sketch or the plans for (a work to be executed)... To intend for a definite purpose." Ideally, as role models and peer advisors, orientation leaders act as guides in helping incoming students create their own game plans and becoming engaged both inside and outside the classroom. Orientation leaders need to understand and be prepared to help incoming students find confidence in their ability to pick classes, both related to their intended major and/or based on exploring interests.

It is important that orientation leaders understand that a student's schedule is the first few brush strokes of his/her collegiate masterpiece. They can remind students that their future schedules and career goals may change during the course of their undergraduate experience. However, outlining the first college semester or academic year is an important starting point in designing their collegiate plan. 
Orientation leaders can reassure students by supporting them through the process of assembling and arranging their course schedules in collaboration with assigned faculty and/or professional advisors during orientation. Orientation leaders should exhibit confidence in the students as designers of their own dreams and encourage them to listen to what Baxter-Magolda (2009) has coined as the "internal voice," or the ability to listen to their gut. With regard to orientation, this can be applied to course and/or an academic major selection that align with students' goals, passions, and interests.

Most students entering college directly from high school have never had to design their own schedules because their courses were selected for them. In college, incoming students have the opportunity to create their own schedule. Orientation leaders consequently are in a unique position to encourage students to explore their curricular options, including the pros and cons of possible schedule options. Orientation leaders should present students with curriculum guides, if available, for the various majors and/or programs of interest to help students begin exploring and selecting appropriate courses. Orientation leaders should proceed cautiously as, under the time constraints of orientation, it can be tempting to tell students what they should take rather than patiently working with students and encouraging them to make informed choices through consultation with their assigned advisor. Below are some suggested training activities for orientation leaders to enable them to effectively address what incoming students might experience or encounter during orientation.

\section{Director/facilitator toolbox}

- Transcript Review

- Have orientation leaders look at their own electronic transcript or advising tool to evaluate where they are on the path to graduation. Walk them through the full advising process and assess their personal progress in relationship to their degree plans. Are there any incongruencies? What other steps should they take? Have they met the requirements necessary for graduation?

- Considering their career goals, what else can they be involved in to become more marketable in their desired field?

If the Discover and Dream phases are implemented effectively, orientation leaders may find that they need to make some adjustments to their plans in order to accomplish their personal dreams. That being said, the facilitators of orientation training need to be aware of campus and extra-curricular opportunities that may help guide orientation leaders in pursuing their interests.

- Survivor: Name of College/University

- Orientation leaders should be well acquainted with campus in order to make effective referrals. During training, orientation leaders can be broken into teams and given clues and a campus map. Following the clues, orientation leaders will find various people and offices around campus. 
This exercise will help them learn about resources that they can refer incoming students to during orientation.

- $\quad$ Case Studies

- Orientation leaders can be broken into groups to review case studies of scenarios they are likely to encounter during orientation, including frustrated students who may "break down, " angry parents who may try to intervene on their students' behalf, and students with unique quirks.

- Design Questions

- $\quad$ Below are sample design questions that directors/facilitators could ask orientation leaders during training.

- What has been the most challenging aspect of designing your own game plan?

- What resources have you sought to help you design your game plan?

- What words of encouragement might you share with a student during the Design phase?

\section{Orientation leaders toolbox - disarm questions}

Below are questions that orientation leaders can ask incoming students.

- What is one thing that you could do this summer to prepare yourself for a successful fall semester?

- What resources do you think you will need to be successful in college, and specifically in this first year?

- What two goals do you have for this academic year, and how do you plan to accomplish them?

\section{Deliver}

The Deliver phase is the implementation step where students take action to carry out their plans. Stanley (2008) noted, "Direction-not intention-determines our destination" (p.14). Orientation leaders can share with incoming students their best advice to overcome roadblocks, but students have to be motivated to act on that advice in order to be successful. Orientation leaders can encourage students to perform a daily check-in: How are we delivering on the goals and standards we have set for ourselves?

During action-packed training days, orientation leaders may feel overwhelmed and even inadequate in fulfilling their roles. It is important that orientation leaders maintain a positive attitude throughout orientation. Training facilitators may prepare orientation leaders by asking, "When things are not going as well as you had hoped, whom do you turn to for assistance? Whom do you turn to in time of adversity? Do you complain and blame, or do you overcome and reframe by maintaining a positive perspective?" As part of developing a sense of self-efficacy, orientation leaders should be guided to focus on learning opportunities and finding solutions, optimizing what is within their control, and knowing when to ask for help. 
- Be A Star Catcher

- Take time at the end of every day or half-day during training to recognize what each team member is doing well. "Remember what gets recognized gets reinforced and what gets reinforced gets repeated" (Harvey \& Lucia, 2011).

- Watch a TEDtalk (http://www.ted.com)

- Example: Simon Sinek: How great leaders inspire action (2009).

- Personalize Postcards

- Have orientation leaders write themselves a note about the kind of orientation leader they want to be. The director can send the note to the orientation leader later on during the orientation season. Likewise, during orientation, leaders can ask students to write a letter of selfencouragement and place it in a self-addressed, stamped envelope during orientation. The orientation leader can send the letter, along with a personalized note from the orientation leader, to the student sometime after the start of the semester.

- Deliver Questions to Ask Orientation Leaders

- What resources might you turn to when facing challenges during orientation sessions?

- Who can help you in carrying out your design or action plan?

- What commitment will you make to help students deliver on their action plans?

\section{Orientation leader toolbox - deliver questions}

Below are sample questions for orientation leaders to ask students during orientation:

- Tell me about a time when you encountered a significant roadblock to your plans. How did you overcome that roadblock?

- Whom can you turn to when things are challenging?

- Whom can you call for help in carrying out your action plan?

\section{Don't Settle}

The final, Don't Settle phase involves challenging students to achieve their full potential by triggering a "virtuous cycle of self improvement" (Bloom et al., 2008, p. 99). During this phase, orientation leaders can enlist Kuh and Associates' (2005) ethos of "positive restlessness" which involves helping students strive to be the best that they can be. Don't Settle phase creates a place where orientation leaders can celebrate their own achievements and the achievements of incoming students with whom they have the privilege of working. This phase also develops a culture in which students are encouraged and expected to constantly strive for excellence. Below are some Don't Settle phase activities that may be incorporated 
into orientation leader training.

\section{Director/facilitator toolbox}

- $\quad$ Role Play

- $\quad$ Pick three people. One person will play the incoming student, one will play the orientation leader, and the third will be the observer who gives supportive yet challenging feedback. Through this activity, orientation leaders will learn the process of self-assessment and constructive criticism in a manner that can develop rapport and respect. These skills will be useful during orientation and will perpetuate the expectation of excellence.

- Reconnect

- Orientation leaders can brainstorm ways to reconnect with students from orientation sessions throughout the summer. (e.g., send follow-up postcards or e-cards).

- $\quad$ Strive to Improve

- Ask how orientation training can be improved in the future. What can I do to be a better orientation leader? What can I do to improve my own life? What can I do to improve the lives of others with whom I've had the privilege to connect?

- Don't Settle Questions to ask orientation leaders

- How would you yourself train a new orientation leader?

- What do you need from your director to be an effective, excellent orientation leader?

- You have done well so far, but what is one thing you can do even better?

\section{Orientation leader toolbox - don't settle questions}

Below are Don't Settle questions that orientation leaders can ask incoming students.

- You have been successful in signing up for classes and meeting new people; now what are some things you can do between now and August to be successful in the fall?

- You are all here at orientation because you have some great accomplishments. In what ways can you continue to develop and contribute to this institution, our campus community, and your new home? 


\section{Conclusion}

Orientation leaders play crucial roles in helping new students begin their transition to college during summer orientation. Therefore, it is important to comprehensively train these student leaders by providing them with information about the institution, while developing the conceptual and relational skills necessary to be effective conveyors of resources to incoming students (Habley, 1986, 1996). This article has demonstrated how the six phases of Appreciative Advising offer a framework to be utilized in orientation leader training to incorporate and emphasizes the informational, conceptual, and relational skill sets desired. This appreciative approach to training student orientation leaders has the power to positively impact new students as well as the orientation leaders themselves.

\section{References}

Bailey-Taylor, A. (2009). Revolutionizing your counseling techniques with appreciative advising. Student Aid Transcript, 20(1), 12-15.

Baxter Magolda, Marcia (2009). Authoring your life: Developing an internal voice to meet life's challenges. Sterling, VA: Stylus Publishing, LLC.

Bloom, J. L., Hutson, B. L., \& He, Y. (2008). The appreciative advising revolution. Champaign, IL: Stipes Publishing.

Boothman, N. (2008). How to make people like you in 90 seconds. New York, NY: Workman Publishing.

Dictionary.com. Retrieved July 2011.

Fippinger, A. (2009, Summer). An appreciative approach to training undergraduate admissions student workers. College and University: Educating the Modern Higher Education Administration Professional, 85(1), 53-56.

Grogan, J. L. (2010). The appreciative tutor. Manuscript submitted for publication. Habley, W. R. (1986). Advisor training: Whatever happened to instructional design? ACT workshop presentation. Iowa City, IA: ACT.

Habley, W. R. (1995). Advisor training in the context of a teaching enhancement center. In R. E. Glennon and F. N. Vowell (Eds.) Academic Advising as a Comprehensive Campus Process. National Academic Advising Association Monograph Series, no. 2. Manhattan, KS: National Academic Advising Association.

Harvey, E., \& Lucia, A. (2011), Retrieved from http://www.walkthetalk.com/blog/2011/03/16/become-an-effective-andrespected-leader/

Hendley, J. (2010). Orientation leader training: An appreciative advising approach. The Journal of College Orientation and Transition, 1(2), 52-55.

Howell, N. (2010). Appreciative advising from the academic advisor's viewpoint: A qualitative study (Unpublished doctoral dissertation). University of Nebraska, Lincoln. 
Improv Encyclopedia. (2007). Retrieved from http://improvencyclopedia.org/games/Greetings.html

Kuh, G. H., Kinzie, J., Schuh, J. H., Whitt, E. J., \& Associates (2005). Student success in college: Creating conditions that matter. San Francisco, CA: Jossey-Bass.

Martin, N. A., \& Bloom, J. L. (2002). Career aspirations \& expeditions: Advancing your career in higher education administration. Champaign, IL: Stipes Publishing.

Sinek, S. (2009). TEDTalk. How great leaders inspire action. Retrieved from http://www.ted.com/talks/lang/eng/simon_sinek_how_great_leaders_inspire_ action.html

Stanley, A. (2008). The principle of the path: How to get from where you are to where you want to be. Nashville, TN: Thomas Nelson.

Traynor, D. S., \& Bloom, J. L. (2009). Reframing career services appointments using appreciative advising. Manuscript submitted for publication. 